\title{
Effect of Mechanical Activation on the Structural Properties of Mn-Doped $\mathrm{Na}_{0.5} \mathrm{Bi}_{0.5} \mathrm{TiO}_{3}$ Ceramics
}

\author{
D. KIRSEVER* AND H. ÖZKAN TOPLAN \\ Sakarya University, Metallurgy and Materials Engineering, 54187 Sakarya, Turkey
}

\begin{abstract}
Piezoelectric ceramics $\left(\mathrm{Na}_{0.5} \mathrm{Bi}_{0.5}\right) \mathrm{TiO}_{3}+0.5 \mathrm{~mol} \% \mathrm{Mn}(\mathrm{Mn}-\mathrm{NBT})$ have been synthesized by mechanical activation of mixed oxides $\mathrm{BiO}_{2}, \mathrm{Na}_{2} \mathrm{CO}_{3}, \mathrm{TiO}_{2}$ and $\mathrm{MnO}$ for $1 \mathrm{~h}$ at room temperature. Non-activated and activated Mn-NBT powders were characterized by using X-ray diffraction and scanning electron microscopy. Also, the mechanical activation-derived Mn-NBT powders were uniaxially pressed and all pellets were sintered at $1000^{\circ} \mathrm{C}$ and $1200^{\circ} \mathrm{C}$ for $2 \mathrm{~h}$ in air atmosphere. The microstructure and phase analysis of sintered pellets was investigated by using scanning electron microscopy and X-ray diffraction.
\end{abstract}

DOI: 10.12693/APhysPolA.129.610

PACS/topics: 81.05.Je

\section{Introduction}

The study of the mechanical properties of polymer composites have made it desirable to choose these materials over traditional materials for numerous types of applications, such as binder constituents in explosives, load-bearing components, and jet engine modules. As the uses of polymer composites, most widely used piezoelectric ceramics contain $\mathrm{PbO}$ as a major component. However, volatilization of toxic $\mathrm{PbO}$ during hightemperature sintering causes environmental pollution. In recent years, the perovskite-structure bismuth sodium titanate $\left(\mathrm{Na}_{0.5} \mathrm{Bi}_{0.5} \mathrm{TiO}_{3}, \mathrm{NBT}\right)$ is considered to be an excellent candidate as a key material of lead-free piezoelectric ceramics $[1,2]$.

NBT is an A-site complex perovskite relaxor ferroelectric structure with a high Curie temperature of $T_{\mathrm{C}}=$ $320^{\circ} \mathrm{C}$, a remanent polarization of $P_{r}=38^{\circ} \mathrm{C} / \mathrm{cm}^{2}$, and a coercive field of $E_{\mathrm{C}}=73 \mathrm{kV} / \mathrm{cm}$ [3]. However, poling of NBT is difficult due to its high coercive field [4]. This problem can be overcome by forming solid solutions with various types compounds and/or doping with oxides [5-10].

Mechanical activation is a solid-state powder processing technique that involves repeated cold welding, fracturing, and rewelding of powder particles in a high-energy ball mill. In this process, a small quantity of the blended elemental powder mixture is loaded into a container along with the grinding media and the whole mass is agitated at a high speed for a predetermined length of time [5]. The mechano-activation treatment might promote: the amorphization of treated material, noticeable change of the microstructure, size and shape of particles, etc. [4, 11]. In this study, the effect of mechanical activation of structural properties of NBT ceramics was studied on $\mathrm{MnO}$ additive.

*corresponding author; e-mail: dkirsever@sakarya.edu.tr

\section{Materials and method}

$\mathrm{Na}_{2} \mathrm{CO}_{3}$ (Emir Kimya), $\mathrm{Bi}_{2} \mathrm{O}_{3}$ (Acros Organics), $\mathrm{TiO}_{2}$ (Riedel-de Haen) and $0.5 \mathrm{~mol} \% \mathrm{MnO}$ (Aldrich) powders, corresponding to the $\left(\mathrm{Na}_{1 / 2} \mathrm{Bi}_{1 / 2}\right) \mathrm{TiO}_{3}$ stoichiometry, were ball milled with alumina balls in a polyethylene bottle for $2 \mathrm{~h}$. The mixture was carried out by a highenergy planetary ball mill (Fristch) with a rotation speed $600 \mathrm{rpm}$. Ball-to-powder weight ratio was adjusted to 20. The precursor milling was carried out for $1 \mathrm{~h}$. Activated and non-activated powders were uniaxially pressed to form pellets of $25 \mathrm{~mm}$ in diameter at $75 \mathrm{MPa}$. The pellets were sintered at 1000 and $1200{ }^{\circ} \mathrm{C}$ for $2 \mathrm{~h}$. X-ray diffraction (XRD) analysis was performed using a Rigaku Ultima X-ray diffractometer and $\mathrm{Cu} K_{\alpha}$ radiation. A JEOL $6060 \mathrm{LV}$ scanning electron microscope (SEM) was used for morphological analysis of non-activated and activated and sintered samples. Also, density of samples were characterized by the Archimedes principle.

\section{Results and discussion}

Figure 1 shows the XRD patterns of non-activated and activated $\mathrm{MnO}-\mathrm{NBT}$ powders and that all diffraction peaks get shorter after mechanical activation. This reflects the partial amorphisation and structural disordering in NBT powders. Mechanical activation has already been reported to amorphize materials. Also, activated NBT powders had $\mathrm{Bi}_{2} \mathrm{O}_{3}, \mathrm{TiO}_{2}$, and $\mathrm{MnO}_{2}$ peaks.

The microstructures of non-activated and activated MnO-NBT powders are given in Fig. 2. After mechanical activation, particle size of powder is smaller and particle morphology of MnO-NBT changes from needle-like to spherical shape.

The XRD patterns of non-activated and activated MnO-NBT samples sintered at 1000 and $1200{ }^{\circ} \mathrm{C}$ for $2 \mathrm{~h}$ are given in Fig. 3. It can be seen that there is no significant difference in diffraction patterns after mechanical activation and different sintering temperatures. All sintered NBT samples possess a single rhombohedral perovskite structure and all peaks belong to NBT phase. 


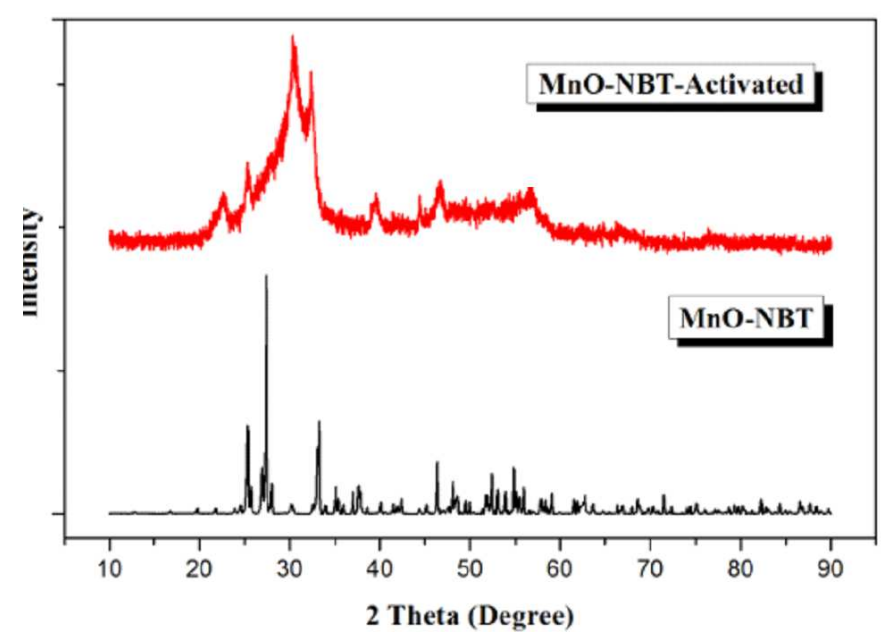

Fig. 1. XRD patterns of activated and non-activated MnO-NBT.
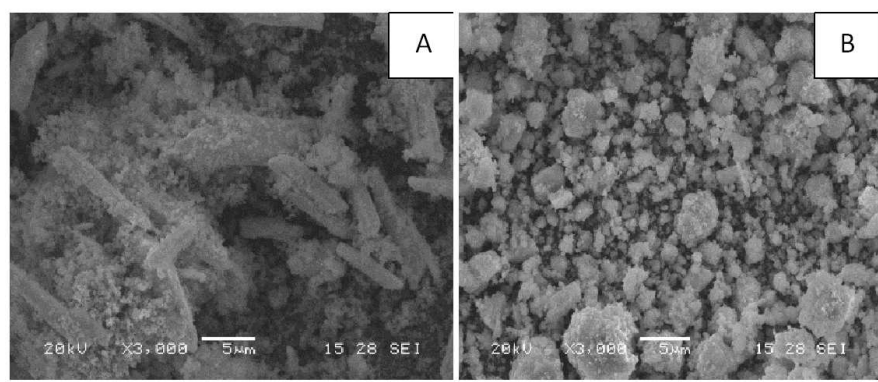

Fig. 2. SEM micrographs of (A) non-activated and (B) activated $\mathrm{MnO}-\mathrm{NBT}$ powders.

Also, Mn ions just diffuse into NBT crystal lattices with a very low concentration. The result is confirmed that most of the Mn ions doped in NBT-based ceramics accumulate in grain boundaries, and the crystal lattices almost have no change.

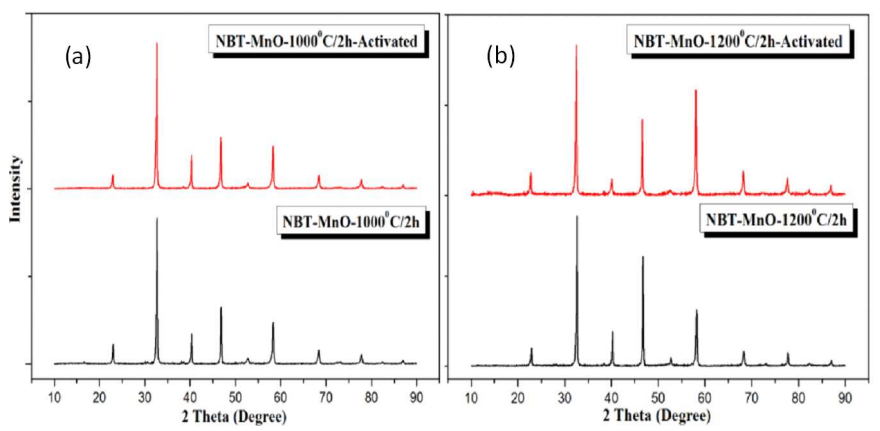

Fig. 3. XRD patterns of MnO-NBT samples sintered at (a) 1000 and (b) $1200^{\circ} \mathrm{C}$ for $2 \mathrm{~h}$.

The pore size and distribution significantly decreased with increasing sintering temperature. It is seen that porosity of Mn-NBT samples decreases with mechanical activation. Grain morphology of MnO-NBT samples is cornered after mechanical activation. Liquid phase sintering is obviously observed.

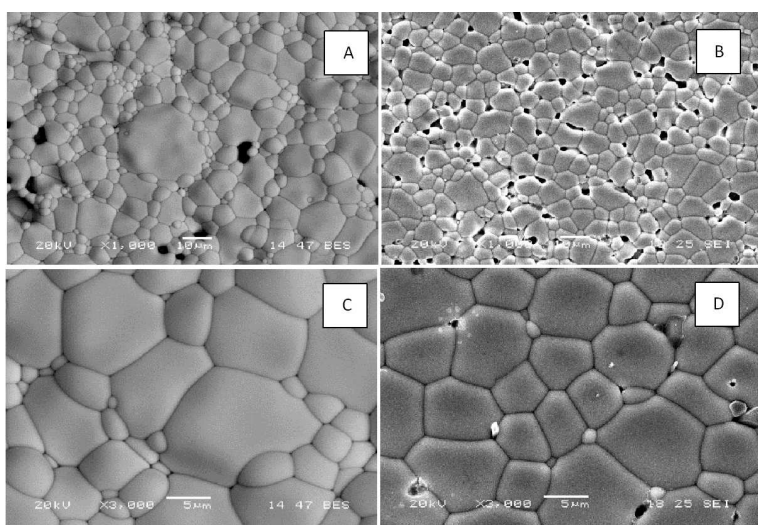

Fig. 4. SEM micrographs of (A),(C) non-activated and $(\mathrm{B}),(\mathrm{D})$ activated $\mathrm{MnO}-\mathrm{NBT}$ samples sintered at $1000^{\circ} \mathrm{C}$ for $2 \mathrm{~h}$.

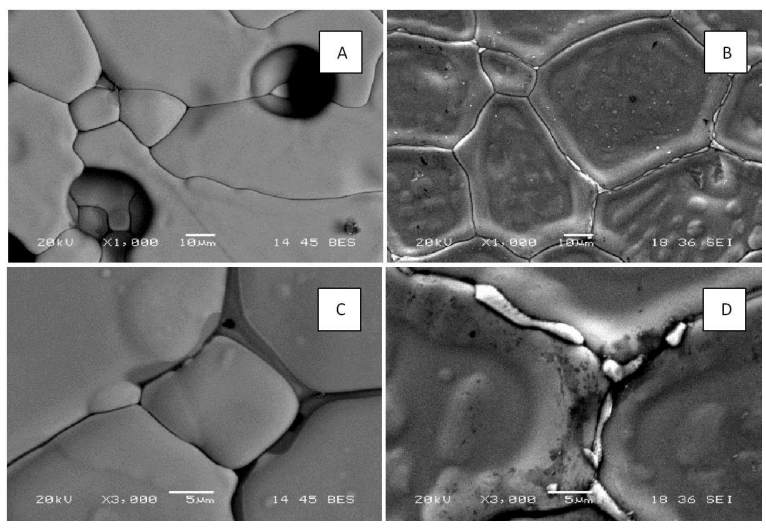

Fig. 5. SEM micrographs of (A),(C) non-activated and (B),(D) activated MnO-NBT samples sintered at $1200^{\circ} \mathrm{C}$ for $2 \mathrm{~h}$.

The density of samples is given in Fig. 6. Firstly, the density of activated $\mathrm{MnO}-\mathrm{NBT}$ samples is higher than non-activated MnO-NBT samples and the highest relative density value of activated MnO-NBT samples is $92.04 \%$ at $1100^{\circ} \mathrm{C}$ for $2 \mathrm{~h}$.

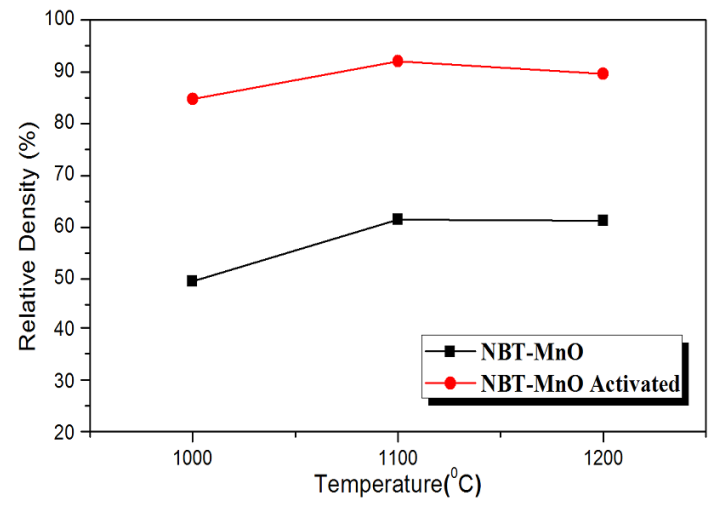

Fig. 6. Density of MnO-NBT samples sintered at $1200^{\circ} \mathrm{C}$ for $2 \mathrm{~h}$. 


\section{Conclusion}

The effect of mechanical activation on sintering and microstructure of NBT based ceramics with $\mathrm{MnO}$ addition was investigated. As the milling time increased, the particle size was reduced and mechanical activation caused amorphization. Also, the density of activated MnO-NBT samples is higher than of non-activated MnO-NBT. Mechanical activation is a low-cost technique and requires a simple processing. As a result, the manufacturing cost for milling and sintering could be reduced due to mechanical activation and lower sintering temperature.

\section{References}

[1] A. Thanaboonsombut, N. Vaneesorn, J. Electroceram. Refract. Ind. Ceram. 21, 414 (2008).

[2] Y. Li, W. Chen, J. Zhou, Q. Xu, H. Sun, R. Xu, Mater. Sci. Eng. B 112, 5 (2004).
[3] Q. Xu, Y.-H. Huang, M. Chen, W. Chen, B.-H. Kim, B.-K. Ahn, J. Phys. Chem. Solids 69, 1996 (2008).

[4] J. Suchanicz, Ferroelectrics 190, 77 (1997).

[5] S.-E. Park, K.S. Hong, J. Mater. Res. 12, 2152 (1997).

[6] T. Takenaka, T. Okuda, K. Takegahara, Ferroelectrics 196, 175 (1997).

[7] K. Maruyama, K. Sakata, T. Takenaka, Jpn. J. Appl. Phys. 30, 2236 (1991).

[8] A. Herabut, A. Safari, J. Am. Ceram. Soc. 80, 2954 (1997).

[9] H. Nagata, T. Takenaka, J. Eur. Ceram. Soc. 21, 1299 (2001).

[10] Z. Yu, V.D. Krstic, B.K. Mukherjee, J. Mater. Sci. 42, 3544 (2007).

[11] C. Suryanarayana, N. Al-Aqeeli, Prog. Mater. Sci. 58, 383 (2013). 